\title{
Transnasal jet ventilation is a useful adjunct to teach fibreoptic intubation: a preliminary report
} [La ventilation en jet transnasale est un complément avantageux à l'enseignement de l'intubation fibroscopique : un rapport préliminaire]

James R. Boyce MD, ${ }^{*}$ Peter D. Waite DDS MD, $†$ Patrick J. Louis DDS MD,$\uparrow$ Timothy J. Ness MD*

Purpose: Fibreoptic intubation (FOI) has become an essential technique in the anesthetic management of patients with difficult airways. Unfortunately, residents may graduate from anesthesiology training programs with insufficient skills in FOI. To enhance resident proficiency at $\mathrm{FOI}$ without compromising patient comfort or safety, the technique of transnasal jet ventilation-assisted FOI was developed. This report describes our initial experience with this technique.

Methods: Sixty-four patients scheduled for oromaxillofacial surgery under nasal endotracheal anesthesia were recruited. Twenty-eight residents at all levels of training performed FOI through the patient's right nostril after the induction of general anesthesia and neuromuscular blockade. Oxygenation and ventilation were maintained by a faculty anesthesiologist using a Sanders device to deliver a jet of oxygen through a nasal trumpet placed in the patient's left nostril. The time from induction until completion of the FOI was recorded. Residents were subsequently queried about the educational benefit of the technique using a standardized questionnaire.

Results: All residents were able to successfully intubate all patients in this study. Thirteen residents successfully performed intubations on three or more occasions with $70 \%$ performing the technique faster on the third trial than on the first. No evidence of hypoxemia, gastric distension, pneumothorax, hemodynamic instability or recall was observed. All respondents to the questionnaire reported that the technique was useful as an educational tool and recommended its use with other residents.

Conclusion: Transnasal jet ventilation-assisted $\mathrm{FOI}$ is a useful method to train residents in $\mathrm{FOI}$ while maximizing patient comfort and safety.
Objectif : L'intubation fibroscopique (IF) est devenue une technique anesthésique essentielle en cas de problèmes d'intubation. Malheureusement, des résidents peuvent devenir anesthésiologistes sans avoir les habiletés nécessaires à l'IF. Pour améliorer leur compétence en IF sans compromettre le confort et la sécurité des patients, la technique d'IF assistée de la ventilation en jet transnasale a été mise au point. Nous décrivons notre première expérience avec cette technique.

Méthode : Nous avons recruté 64 patients devant subir une opération oro-maxillo-faciale sous anesthésie endotrachéale nasale. Vingthuit résidents de tous les niveaux de formation ont réalisé une IF utilisant la narine droite du patient, après l'induction de l'anesthésie générale et le bloc neuromusculaire. L'oxygénation et la ventilation ont été maintenues par un anesthésiologiste à l'aide d'un appareil Sanders qui distribue un jet d'oxygène au travers d'une canule nasale placée dans la narine gauche du patient. Le temps écoulé entre l'induction de l'anesthésie et la fin de l'IF a été noté. Les résidents ont répondu ensuite à un questionnaire normalisé sur les avantages éducatifs de la technique.

Résultats : Tous les résidents ont réussi à intuber tous les patients de l'étude. Treize résidents ont réussi des intubations en trois occasions ou plus ; $70 \%$ d'entre eux ont réalisé la technique plus vite au troisième essai qu'au premier. Aucune évidence d'hypoxémie, de distension gastrique, de pneumothorax, d'instabilité hémodynamique ou de prise de conscience n'a été observée. Tous les répondants au questionnaire ont reconnu que la technique était utile à la formation et ont recommandé son usage par les autres résidents.

Conclusion : L'IF assistée de ventilation en jet transnasale est une méthode de formation utile des résidents et maximise le confort et la sécurité du patient.

From the Departments of Anesthesiology* and Oral and Maxillofacial Surgery, $†$ University of Alabama at Birmingham, Birmingham, Alabama, USA.

Address correspondence to: Dr. James R. Boyce, Department of Anesthesiology, JT 845Q

University of Alabama at Birmingham, 619 South 19th Street, Birmingham, AL 35294-6810, USA. Phone: 205-934-6948;

Fax: 205-975-3080; E-mail: james.boyce@ccc.uab.edu

Accepted for publication May 13, 2003

Revision accepted September 8, 2003. 


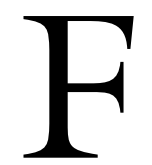

IBREOPTIC intubation (FOI) has become an essential technique in the management of the difficult airway. ${ }^{1}$ The guidelines published by the American Society of Anesthesiologists ${ }^{2}$ (ASA) and recent comprehensive reports ${ }^{3}$ cite the importance of FOI for the successful management of many airway challenges. Fibreoptic equipment is now typically available in most anesthesiology departments, and expertise in its use is an important objective for residency training in anesthesia. Unfortunately, many residents graduate from residency programs with insufficient skills in the use of FOI equipment. ${ }^{4}$ Airway management workshops are helpful, providing candidates with hands-on experience in the use of flexible fibreoptic laryngoscopes and bronchoscopes, employing manikins, models, ${ }^{5}$ and virtual reality airway simulators ${ }^{6}$ to provide the educational experience needed for proficiency. However, in the operating room (OR) setting, the resident's opportunities to gain live experience in flexible FOIs are often inadequate. The reasons for this are severalfold. First, when a FOI is necessary to intubate a patient whose airway evaluation predicts a clinical challenge, the most experienced endoscopist, usually the faculty anesthesiologist, often takes over in order to maximize patient safety. If an inexperienced resident does get an opportunity to attempt the FOI in such a clinical setting, the urgency of the situation and the anxiety of the faculty anesthesiologist may limit both the time for the resident to gain valuable experience and the quality of the educational instruction that he or she may receive. On the other hand, if the airway is not challenging it may be inappropriate to recruit a patient for an awake FOI solely for training purposes.

Recently, we described a technique to teach FOI under controlled conditions, maximizing the educational experience for the resident as well as safety and comfort for the patient. ${ }^{7}$ The present communication describes the procedure in more detail and our experience teaching first to third year residents with this technique in anesthetized patients. The report also illustrates the learning curve of residents who were instructed by this technique on three or more occasions.

\section{Methods}

Following approval of the protocol by the University of Alabama at Birmingham Institutional Board for Human Studies, ASA physical status class I and II patients presenting for oral-maxillofacial surgery were recruited. Exclusion criteria were patients whose evaluation predicted a difficult airway, body mass index > 31, pregnancy, gastric reflux, and significant pulmonary or cardiovascular disease. Patients with obstructive supraglottic pathology were also excluded as were those with abnormal laboratory data. In all the cases there was a surgical request for nasal endotracheal anesthesia.

Each patient was placed on the OR table in a $20^{\circ}$ reverse Trendelenburg position and sedated with ip midazolam after routine noninvasive monitors were applied. One millilitre of a solution of $2 \%$ lidocaine and $0.1 \%$ phenylephrine was instilled in both nasal cavities. Induction of anesthesia was accomplished with fentanyl $3 \mu \mathrm{g} \cdot \mathrm{kg}^{-1}$, lidocaine $1.5 \mathrm{mg} \cdot \mathrm{kg}^{-1}$, sodium thiopental 3 to $5 \mathrm{mg} \cdot \mathrm{kg}^{-1}$ and rocuronium 0.7 $\mathrm{mg} \cdot \mathrm{kg}^{-1}$ followed by mask-bag ventilation with $100 \%$ oxygen. When anesthesia and neuromuscular paralysis were established, a nasal trumpet, well lubricated with lidocaine jelly was introduced into the left nasal cavity. Ventilation was then accomplished by manual jet ventilation into the lumen of the nasal trumpet using a Sanders jetting device (Mannujet III, VBM Medizintechnic Lans, Sulz, Germany) with a 14gauge iv catheter attached to the Luer lock of the noncompliant tubing. The driving oxygen pressure was started at 25 psi and increased, as needed, using the reducing valve of the jetting device. If chest expansion was not adequate with each jet inflation, the nasal trumpet was withdrawn and rotated slightly or the driving pressure was increased and jetting resumed. Additional $i v$ hypnotics and opioids were administered as needed according to the vital signs. Eyes were protected with ointment and tape.

The residents were instructed in the basics of fibreoptic bronchoscopy in the OR prior to the patient's arrival. The fundamental actions of the flexible bronchoscope tip were demonstrated and a warmed nasal RAE® endotracheal tube was advanced to the most proximal portion of the endoscope (Olympus LF-2, Melville, NY, USA). Most of the instruction, however, was communicated during the endoscopic attempts by the residents. A teaching camera attachment (Olympus OTV-S5) was connected to the eyepiece of the bronchoscope. Concurrent with nasal jet ventilation by the faculty anesthesiologist, the resident proceeded with endoscopy through the opposite nostril (Figure 1). When the resident had visualized the epiglottis indicating proximity to the glottic aperture, the faculty anesthesiologist changed the intermittent jetting to a low continuous flow of oxygen from the jetting device. After successful cannulation of the trachea the endoscope was removed and the circle system connected to establish positive pressure ventilation. The presence of the end tidal $\mathrm{CO}_{2}$ waveform confirmed successful FOI. The time from the beginning of the $i v$ induction to the appearance of the first end- 


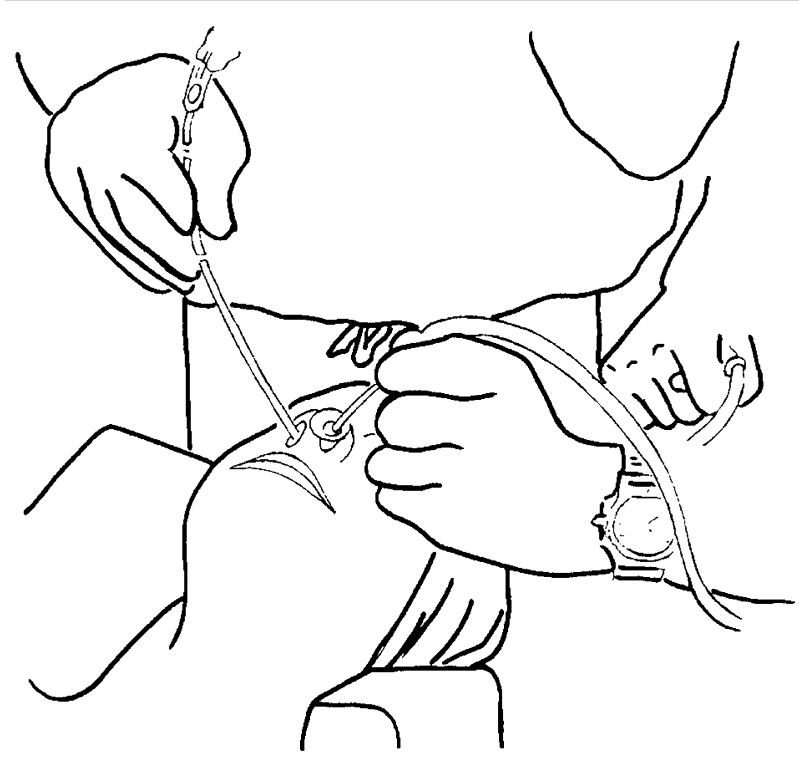

FIGURE 1 Illustration demonstrating the transnasal jet ventilation-assisted fibreoptic intubation technique. Concurrent with transnasal jet ventilation by the attending anesthesiologist, the resident proceeds with endoscopy through the opposite nostril.

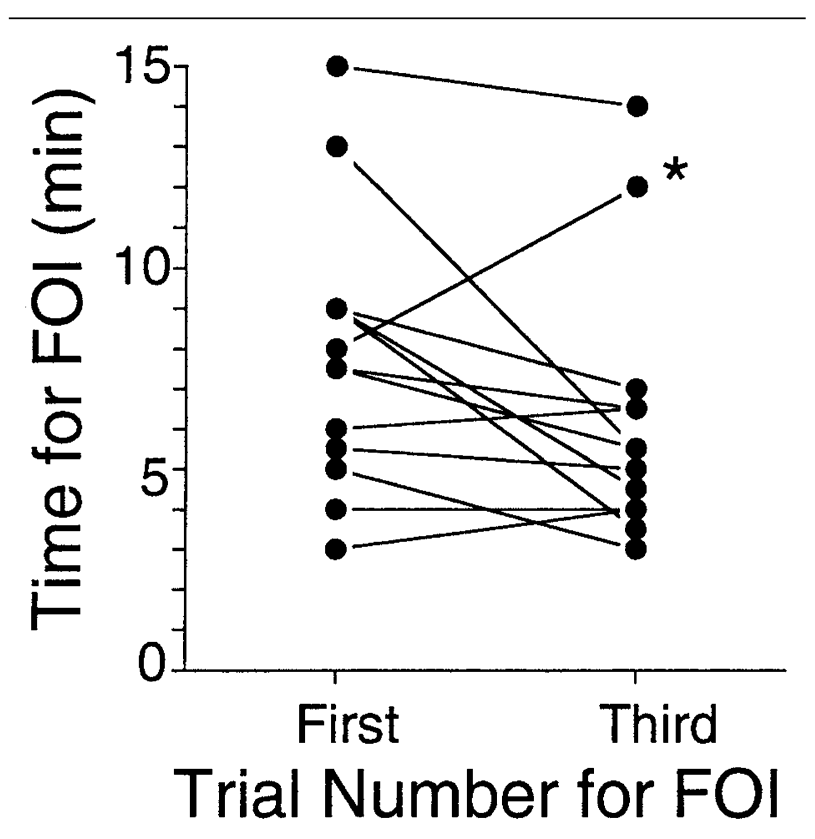

FIGURE 2 Evolution of duration of fibreoptic intubation (FOI) in 13 individual residents. Overall duration of FOI decreased between the first and third FOI $(P=0.05$; Wilcoxon rank-sign test). ${ }^{*}$ One resident took markedly more time on the third FOI because of upper airway bleeding on that attempt.

dents (five were first year) participated on multiple occasions, and their first and third intubation times were compared. Nine of the 13 residents improved their technique as demonstrated by successfully completing the third FOI in a shorter period of time than the first. One performed the third FOI in the same amount of time as the first and three took longer (Figure 2). The one resident whose third FOI took markedly longer than the first FOI encountered bleeding that obscured his vision on that attempt. Statistical analysis demonstrated an overall improvement in performance from the first FOI to the third $(P=0.05)$.

There were no adverse events encountered in the study. When patients were examined clinically and occasionally with chest $x$-rays in the postanesthesia care unit, no cases of gastric distention, pneumothorax, pneumomediastinum, or hypoxemia were identified. In all patients, the capillary oxygen saturation $\left(\mathrm{SpO}_{2}\right)$ remained at or above $98 \%$. Two patients had minor epistaxis that was self-limited. Five patients required adjustments of the nasal trumpet (withdrawing slightly or rotating) to maximize chest expansion with the jet ventilation. In five patients the nasal trum-

\section{Results}

Twenty-eight anesthesiology residents at all levels of training and 64 patients participated in the study. Six of the first-year residents were performing a FOI for the first time. Most of the residents who participated had performed fewer than ten FOIs. Mean duration of FOI was six minutes (range $3.23-15 \mathrm{~min}$ ). Thirteen resi- 


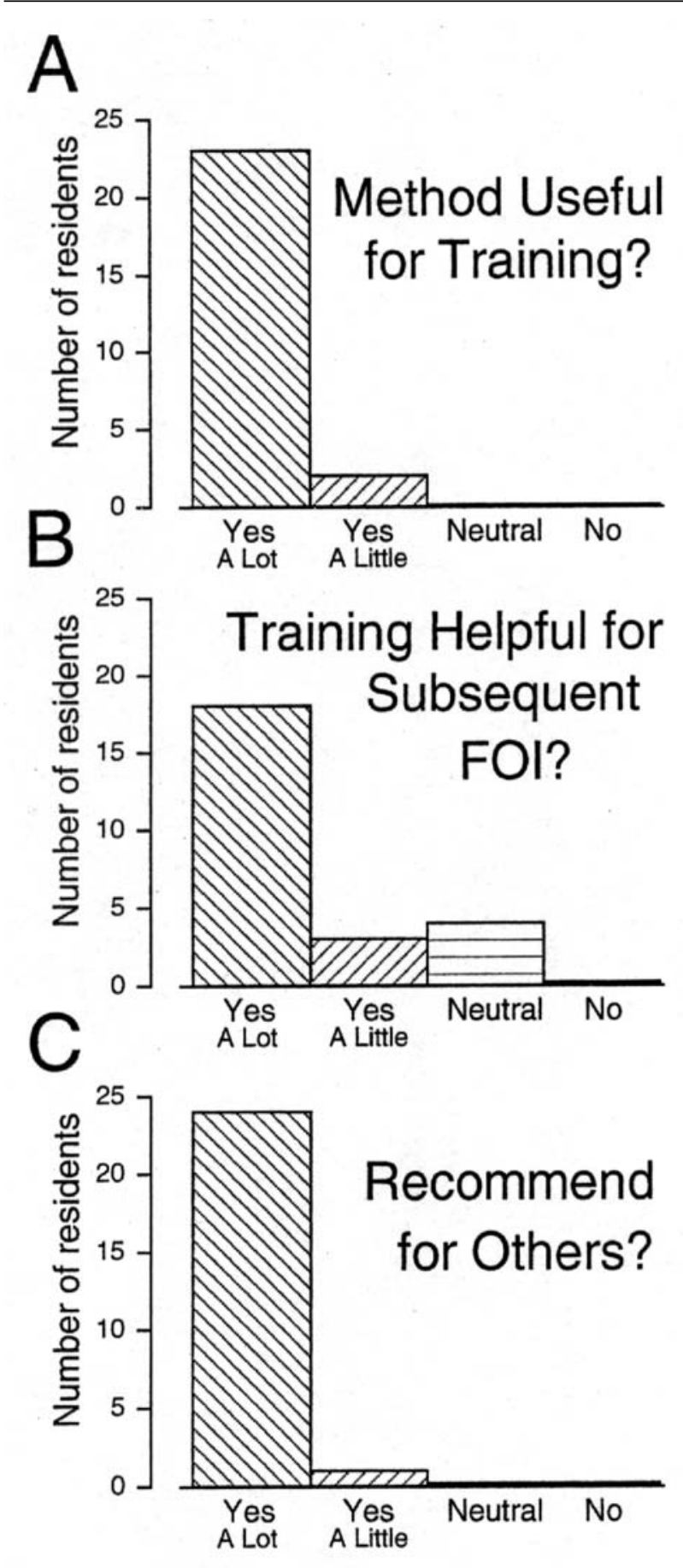

FIGURE 3 Residents reported a positive educational value of the transnasal jet ventilation-assisted fibreoptic intubation technique. pet had to be withdrawn slightly to allow an unobstructed view of the cords even though ventilation was satisfactory. The highest end-tidal $\mathrm{CO}_{2}$ recorded after successful FOI was $48 \mathrm{mmHg}$. Twenty patients required supplemental hypnotic (sodium thiopental or propofol) during the course of FOI. No patient experienced recall.

A total of 25 of the 28 residents who had experienced the technique responded to the questionnaire regarding the educational value of the technique; three graduates could not be reached as they had left the program. Responses were overwhelmingly positive with no negative responses and predominantly high endorsements of the educational value of the technique (Figure 3).

\section{Discussion}

This study suggests that transnasal jet ventilation can be a useful adjunct to teach FOI. Many residents who were performing their first FOI were able to focus on learning the fundamentals of endoscopy without distractions, knowing the patients were fully anesthetized and oxygenated. The reduction of time required for successful FOI for most residents performing three endoscopies would suggest a beneficial learning effect. All residents who responded to the questionnaire affirmed the value of the technique for developing skills in FOI.

The importance of patient selection should be emphasized. The technique, when used for training purposes, should be utilized primarily in patients whose preoperative evaluation would predict easy unobstructed mask ventilation. Therefore, patients with any glottic or supraglottic pathology such as laryngeal cancer or papillomata, base of tongue tumours, retropharyngeal abscess, or any obstructive lesion at the larynx or proximal to it, should not be candidates for this technique.

We arbitrarily placed our patients in a slight reverse Trendelenburg position to maximize chest expansion with minimal jetting pressures. It has been shown in morbidly obese patients that total respiratory compliance is greater in the reverse Trendelenburg position than in the supine position, ${ }^{8}$ and the same benefit may apply to the non-obese patient as well.

With the camera attachment the faculty anesthesiologist can provide real time guidance and direction to the resident and still maintain adequate oxygenation and ventilation with the transnasal jet ventilation. Often, when the resident had advanced the tip of the bronchoscope close to the glottic aperture, a low continuous flow of oxygen from the jetting device separated the soft tissues such as the epiglottis from the posterior pharyngeal 
wall and enhanced the view of the cords, expediting successful entry into the tracheal lumen.

Whenever jet ventilation is employed as part of the anesthetic technique, barotrauma is always a concern. The absence of complications related to barotrauma in our study is probably due to two factors. First, since the oral cavity is not sealed, any increased pressure in the oropharynx will easily escape to ambient air through the mouth. Often, with each jet inflation, gas would escape through the lips as well as inflate the lungs. Second, with the vocal cords abducted due to neuromuscular blockade, the jet stream leaving the distal end of the nasal trumpet has unobstructed access to the tracheal lumen. Without neuromuscular paralysis, stimulation by the jet stream can activate the glottic-closure reflex ${ }^{9}$ causing airway obstruction. For this reason, succinylcholine with its early recovery time may not be an appropriate neuromuscular blocker for this procedure as many of the residents' FOI attempts exceeded the duration of muscle paralysis afforded by this agent.

In summary, we have shown that transnasal jet ventilation may be a useful adjunct in teaching FOI. Patient safety and acceptance was demonstrated by adequate oxygenation and ventilation indices, minimal complications, and absence of patient recall. All residents surveyed on this educational experience affirmed its value.

\section{References}

1 Benumof JL. Management of the difficult adult airway. With special emphasis on awake tracheal intubation. Anesthesiology 1991; 75: 1087-110.

2 American Society of Anesthesiologists Task Force. Practice guidelines for management of the difficult airway. A report by the American Society of Anesthesiologists Task Force on Management of the difficult airway. Anesthesiology 1993; 78: 597-602.

3 Morris IR. Fibreoptic intubation. Can J Anaesth 1994; 41: 996-1008.

4 Koppel JN, Reed AP. Formal instruction in difficult airway management. A survey of anesthesiology residency programs. Anesthesiology 1995; 83: 1343-6.

5 Naik VN, Matsumoto, ED, Houston PL, et al. Fiberoptic orotracheal intubation on anesthetized patients. Do manipulation skills learned on a simple model transfer into the operating room? Anesthesiology 2001; 95: 343-8.

6 Rowe $R$, Cohen RA. An evaluation of a virtual reality airway simulator. Anesth Analg 2002; 95: 62-6.

7 Boyce JR. Effectiveness of transnasal jet ventilation-a teaching aid (Letter). Can J Anesth 2001; 48: 716.

8 Perilli V, Sollazzi L, Bozza P, et al. The effects of the reverse Trendelenburg position on respiratory mechanics and blood gases in morbidly obese patients during bariatric surgery. Anesth Analg 2000; 91: 1520-5.

9 Ikari T, Sasaki CT. Glottic closure reflex: control mechanisms. Ann Otol 1980; 89: 220-4. 